\title{
A new apparatus for one-way locomotor avoidance without handling'
}

\author{
W. MARVIN DAVIS, MARIO BABBINI AND BEN D. HUNEYCUTT \\ UNIVERSITY OF MISSISSIPPI SCHOOL OF PHARMACY
}

A four compartment box suitable for continued one-way avoidance without interruption and handling for return to a starting compartment was described. Improved learning obtained with it in comparison to the learning when only two adjoining compartments were used as a conventional shuttle box was reported. The significance of this comparison to the question of why more rats fail to acquire the avoidance response in a shuttle box than in a one-way box was discussed.

Learning an avoidance response in a shuttle box is well known to be difficult for many rats, especially in comparison to the rapid learning achieved in a one-way box (Theios \& Dunaway, 1964). Because of our experiences with this problem (as well as others) associated with shuttle boxes, we have sought to design an alternative for psychopharmacological experiments. The two compartment one-way box was deemed unsatisfactory for this purpose because of the necessity of handling the Ss between trials, thus adding a variable of uncertain influence on drug effects. Various Es have devised different techniques to facilitate avoidance acquisition and to investigate the relative importance of the experimental variables in hindering such learning in a shuttle box. The former purpose has been accomplished by several means, i.e., with a different US in a shuttle box (Ray, 1966) or with a different CR situation as in an automated jump box (Baum, 1965). However, few of such alternative procedures have helped to clarify why the acquisition of avoidance responses is very slow or even impossible for many rats in a shuttle box. In fact, some of these techniques, by requiring a different response to be performed by rats, i.e., jumping upon an elevated platform (Baum, 1965), are no longer directly comparable to the shuttle box situation. Some others, by introducing additional stimuli into the experimental procedure, i.e., handling the Ss (Theios \& Dunaway, 1964) or rotating the cage (Baum \& Bobrow, 1965) make the results difficult to compare to those with the shuttle box because of the new variables. We have designed a four compartment box to obviate disadvantages of two compartment boxes, both one-way and shuttle. Since it could be used alternatively in shuttle or one-way fashion, it was also well suited for a comparison of these two modes of avoidance training under conditions more Identical than in previous comparisons.

\section{Apparaius and Procedure}

The apparatus consisted of a square box, 30 in. $x$ 30 in. $x 12$ in. high. It was subdivided into four $15 \times 15$ in. compartments by four partitions, each equipped with a vertically operating sliding door. The doors were raised by two motors placed outside the box and connected to each through wires, and they were lowered by deactivating the motors. The floor of each compartment contained a removable shock grid of the type originated by Dinsmoor (1958) made of $5 / 8 \mathrm{in}$. diameter tubing set at intervals of $3 / 8 \mathrm{in}$. The grids were positioned so that the orientation was the same relative to the exit door of each compartment. Each grid could be separately charged.

The shock stimulus (US) was delivered through a motor operated grid scrambler. All compartments were painted white except for the doors, which were painted black on the "exit side" only when the box was used for one-way avoidance, on both sides when the box was used for shuttle avoidance. The ceiling was a transparent Plexiglas panel through which the E could observe the animal with the aid of an inclined mirror $3 \mathrm{ft}$ above the box. A buzzer mounted over the center of the apparatus provided the CS, a white noise of middle intensity.

The training procedure was partially automated. The E could start the CS by pushing a button that caused simultaneously the onset of the buzzer, the raising of the door, and the timing of the CS interval which was 7 sec. The US onset automatically coincided with the offset of the CS. When the $S$ avoided or escaped, the door was lowered by $\mathrm{E}$ just after the animal passed through. If the animal responded before onset of US, the $\mathrm{E}$ turned off CS immediately. For shuttle type conditioning only two adjacent compartments were used with alternation of shock between the two, while for one-way conditioning all four compartments of the apparatus were employed and the grids were electrified in a clockwise succession. Only the door facing the next compartment was raised at the onset of the buzzer, so the $S$ could escape or avoid only in one direction.

Two experiments were performed with this apparatus. The first was particularly for the sake of a direct comparison between the shuttle and the one-way box situation; the second was to test further the advantages of the new apparatus as a four compartment one-way box. For both experiments 90-120 day Holtzman male rats were used. They were housed in community cages with food and water available ad libitum. In the first experiment 88 Ss were divided into two equal groups. Those of the first group were trained in the conventional shuttle box manner, those of the second in the one-way fashion. Each $S$ was allowed to explore the apparatus for $3 \mathrm{~min}$ before beginning the training. All Ss were trained to a performance criterion of 10 avoidance responses in 12 trials, or to a maximum of 90 trials. The intertrial 
Table 1. Means and Standard Deviations

\begin{tabular}{|c|c|c|c|c|c|}
\hline & \multicolumn{3}{|c|}{ Exporiment I } & \multicolumn{2}{|r|}{ Experiment } \\
\hline & & $\begin{array}{l}\text { Shuttle } \\
\text { Training }\end{array}$ & $\begin{array}{l}\text { One-woy } \\
\text { Training }\end{array}$ & $\mathbf{p}$ & $\begin{array}{l}\text { One-way } \\
\text { Training }\end{array}$ \\
\hline Subjects & $\mathbf{N}$ & 44 & 44 & & 17 \\
\hline $\begin{array}{l}\text { Ss Reaching } \\
\text { the Criterion }\end{array}$ & $\begin{array}{l}N \\
\%\end{array}$ & $\begin{array}{l}18 \\
(40.9)\end{array}$ & $\begin{array}{l}36 \\
(85.7)\end{array}$ & $<0.01$ & $\begin{array}{c}17 \\
(100)\end{array}$ \\
\hline $\begin{array}{l}\text { Trial of First } \\
\text { Avoidance }\end{array}$ & $\begin{array}{l}M \\
S D\end{array}$ & $\begin{array}{r}30.22 \\
2.50\end{array}$ & $\begin{array}{l}9.59 \\
0.51\end{array}$ & $<0.01$ & $\begin{array}{r}10.02 \\
1.89\end{array}$ \\
\hline $\begin{array}{l}\text { Total Trials } \\
\text { to Criterion }\end{array}$ & $\begin{array}{l}M \\
S D\end{array}$ & $\begin{array}{r}36.27 \\
3.40\end{array}$ & $\begin{array}{r}43.73 \\
3.70\end{array}$ & N.S. & $\begin{array}{r}38.58 \\
6.92\end{array}$ \\
\hline $\begin{array}{l}\text { Total Errors } \\
\text { to Criterion }\end{array}$ & $\begin{array}{l}M \\
S D\end{array}$ & $\begin{array}{r}32.55 \\
2.68\end{array}$ & $\begin{array}{r}28.97 \\
2.54\end{array}$ & N.S. & $\begin{array}{r}29.52 \\
5.20\end{array}$ \\
\hline
\end{tabular}

interval ranged randomly between 20 and $40 \mathrm{sec}$. In the second experiment 17 Ss were used. They were trained in the one-way fashion, the general procedure being very similar to that of the first experiment except that Ss received 20 trials every $48 \mathrm{~h}$ until the oriterion was reached or until 100 trials had been given.

\section{Results and Discussion}

The results of both experiments in terms of Ss reaching the 10/12 criterion and values of three parameters commonly used as indices of avoidance acquisition rate are shown in Table 1. The percentage of Ss that falled to achieve the criterion in the shuttle box was quite high, but in accordance with results reported by others (Bindra, 1961). With our one-way procedure this percentage was much reduced, the difference between the two being highly significant $\left(X^{2}=6.92\right)$. A similar evidence of improvement appeared in the data of the second experiment in which all Ss reached the criterion within 100 trials. This showed that with our apparatus all rats can learn a consistent avoldance behavior in a limited time if an appropriate training schedule is used.

The difference between one-way and shuttle-trained groups for the number of trials to the first avoidance was highly significant $(t=8.01)$. The mean values of this parameter (as well as the other two) were very similar between the first and second experiments (Table 1). Moreover, another group of 18 animals trained with the same experimental procedure for only 30 consecutive trials had shown a mean for trials to first avoidance of 10.11 ( $S D=1.85$ ), thus further confirming the reliability of this result. It is interesting to note that even though the rats began avoidance earlier in our apparatus than in the shuttle box, the mean for the trial of the first avoidance was still higher than that commonly reported for other one-way avoidance procedures, 1.e., about four according to several authors (Thelos \& Dunaway, 1964; Ray, 1966; Baum \& Bobrow, 1966). This result, together with the lack of significant differences in the other two variables considered (total trials to criterion, $t=1.29$; total errors to criterion, $t=0.87$ ), suggests that learning in our apparatus is faster and easier than in the shuttle box, but not so rapid as in conventional one-way avoidance using two compartment boxes, often with clearly differing "shock" and "safe" areas. This is not surprising because reaching a distinctive safety area or being handled shortly after the response can become powerful conditioned reinforcers. Moreover, Knapp (1963) has recently shown that avoldance learning is retarded by similarity between escape and shock boxes in comparison with a situation of contrasting boxes.

All experiments performed by different authors to investigate reasons for the difficulty of learning in the shuttle box are open to the same criticism; several variables are concurrently manipulated and the relative importance of each is difficult to assess. With our new apparatus it has been possible to study the relevance of only one variable (1.e., the direction of movement) and to show that this powerfully affects avoidance learning in rats. The apparatus described above presents another procedural advantage, being adaptable to fully automated one-way avoidance training which cannot be accomplished with conventional one-way avoidance in a two compartment box.

\section{References}

Baum, M. An automated apparatus for the avoidance training of rats. Psychol. Rep., 1965, 16, 1205-1211.

Baum, M., \& Bobrow, S. A. An automated analogue of the one-way Miller-type avoidance box. Psychon. Sci., 1966, 5, 361-362.

Bindra, D. Components of general activity and the analysis of behavior. Psychol. Rev., 1961, 68, 205-215.

Dinsmoor, J. A. A new shock grid for rats. J. exp. Anal. Behav., 1958, 1, 264.

Knapp, R. K. Acquisition and extinction of avoidance with similar and different shock and escape situations. J. comp. physiol. Psychol., 1965, 60, 272-273.

Ray, A. J., Jr. Shuttle avoidance: Rapid acquisition by rats to a pressurized air unconditioned stimulus. Psychon. Sci., 1966, 5 , 29-30.

Theios, J., \& Dunaway, J. E. One-way versus shuttle avoidance conditioning. Psychon. Sci., 1964, 1, 251-252.

\section{Note}

1. This research was supported by USPHS grant no. MH-11295-01. 